\title{
Literary plants
}

\author{
Plants are often the subjects of paintings but their involvement in literature and drama is rarely centre \\ stage. With the inauguration of a new literary festival it is time for a reassessment of the plant kingdom's \\ dramatic potential.
}

The Royal Botanic Gardens at Kew engaged in a new venture this September holding the Write on Kew literary festival. Supplying the tranquillity of more remote UK festival venues such as Hay-on-Wye or Cheltenham while less than 10 miles from central London it provided an easy opportunity to bring together scientific and artistic endeavours, which has long been a function of Kew. As Anne Elletson and Tanya Burgess, directors of programming for Write on Kew put it: "Books and nature both stimulate the imagination and take us to new and unexpected places; and what better place than Kew Gardens, a science institution and botanic garden to provide a new London platform for debate, discovery, creativity and a flow of ideas."

How well was this aim achieved? The roster of authors taking part was certainly impressive, mixing literary big hitters like Margaret Atwood and Howard Jacobson, with historians such as John Julius Norwich, the chef Raymond Blanc and a selection of gardeners including Thomas Pakenham and Tim Smit. Science was well represented including Matt Ridley discussing genetics and evolution, and President of the Royal Society Paul Nurse contrasting Darwin's view of creation with Milton's. There was even a broadcast of the BBC Radio 4's science program Inside Science involving a number of Kew scientists including the scientific director Kathy Willis.

One topic that might have been expected to feature in such a festival is the role played by plants in literature; the closest that Write on Kew came was novelist Penelope Lively discussing how writers have responded to gardens and gardening. That isn't quite the same thing. Philip Larkin's poem 'The Mower' dwells more on the single hedgehog that his machine accidentally kills than its deliberate effects on thousands of blades of grass. Equally Beatrix Potter's interest in Mr McGregor's garden, despite her skill as a botanical illustrator, is as the backdrop for the antics of various jacket- and shoe-wearing rabbits. Is this a reflection of the general 'plant blindness' of society?

Many authors have written from the point of view of an animal or created animals with distinctly human characteristics.
Anthropomorphic plants are harder to find and generally confined to the realm of fantasy. Possibly the most realistic occur in Lewis Carroll's Through the Looking-Glass. The roses, violets and daisies that Alice encounters there are 'real' flowers with 'real' preoccupations like a fear of being picked or of their petals fading. They only fail to talk, as the Tiger-lily explains, for lack of "anyone worth talking to".

Alice's plants are correctly rooted to the spot unlike John Wyndham's triffids, or Groot from Marvel Comic's Guardians of the Galaxy whose most 'planty' features are limited conversation and the ability to regrow from a fragment of his body. Perhaps Groot is not a plant at all but, like Tolkien's Ents, from a race of animals that has become increasingly "treeish". Into this category should also go the Tummy-belly men encountered in Brian Aldiss's Hothouse set on an earth of the far future where planetary warming has resulted in globespanning tropical forest including trees that form symbiotic relations with these humanoid creatures.

Such animate plants hardly represent the reality of the plant kingdom any more than the beanstalk that grows overnight from Jack's discarded (and magical) beans, or Enid Blyton's portal to other worlds The Magic Faraway Tree with its collection of bizarre inhabitants such as Moonface and the Saucepan Man. Both might be distant offshoots of Yggdrasil, the 'world tree' of Norse mythology, but they are not examples of authors putting actual plants at the centre of their action.

Where plants often occur is as representatives of more abstract concepts. Anton Chekhov's cherry orchard serves as a symbol of the wealth and status of a crumbling Russian aristocracy sold to the son of a former serf to pay outstanding debts, and ultimately destroyed. In Raymond Chandler's The Big Sleep the elderly General Sternwood is confined to a conservatory filled with orchids whose superheated environment, gaudy but often deceptive appearance and semi-parasitic nature should have alerted Philip Marlowe to the moral corruption he will subsequently uncover. Similarly Daphne du Maurier surrounds Max de Winter's house Manderley with rhododendrons, warning that like the shrubs her narrator is an alien invader of the territory of Max's first wife, Rebecca.

However, it is in verse that plants are most often employed as proxies. Allusions to fruits as temptation abound, either directly referencing the tree in the Garden of Eden - "that tree whose fruit threw death on else immortal us" as John Donne put it - or obliquely such as the cornucopia of succulent but fatally addictive wares for sale at Christina Rossetti's goblin market.

In the traditional ballad 'Barbara Allen' a rose and a briar represent undying love between the all too mortal protagonists. Such intertwinings are common enough to have been satirized by Michael Flanders and Donald Swann in their song 'Misalliance' about the racial prejudice encountered by a honeysuckle and a bindweed because their spiral stems have opposite handedness. Thankfully Don Paterson's poem 'Two Trees', about the grafting and subsequent separation of an orange and a lemon tree, confounds such clichés with the reminder that "trees don't weep or ache or shout. And trees are all this poem is about."

To encounter a story where plants play a central role one need only go to the cinema to see the latest film from director Ridley Scott. The Martian is an adaption of Andy Weir's book and although science fiction, is of the 'hard' kind that attempts to remain based on science fact. Here the botanist and astronaut Mark Watney is marooned on Mars and must work out how to both summon a rescue and survive until it arrives. An answer lies in the potatoes that he and his crewmates had brought along for a Thanksgiving dinner and much of the early action centres around his creation of a soil that can support their growth and an irrigation system to water them.

Explicit and accurate depictions of plants (and plant biologists) are rare in literature and every one should be cherished as a blow against the dismissal of flora as selfrenewing scenery. Let us hope that Write on Kew will continue, that it will inspire events at other botanic gardens, and that by bringing authors and plants together it can secure more starring roles for plants. 